\title{
My life after death: connecting the field, the findings and the feelings
}

\author{
By Kate Woodthorpe (University of Sheffield)
}

This paper is an account of an emotional journey that took place alongside an ethnographic study of the contemporary cemetery landscape. It seeks to highlight the importance of conducting empirical research as a 'rite of passage', leading to the role of a researcher, by examining the connection between data, the human researcher, and the analysis. Furthermore, this paper argues that the emotionality of the research process needs to be incorporated into discussions of methodology and analysis to enable researchers to produce high-quality social research.

\section{Introduction}

It has been argued that not only is it implausible for a researcher to have an analytic distance from the data and analysis they are generating, but also that it is fundamentally impossible (Kreiger 1996). Throughout my fieldwork I was made aware of the difficulties surrounding being 'professional' and 'accurate' as a social researcher. This was further compounded by my realisation that facing death and grief on a daily basis was having a profound effect on how I felt about the prospect of the people I cared about dying, yet to date 'relatively little systematic attention is paid to the emotional... work that frame[s] the fieldwork experience' (Coffey 1999:2). Through this reflexive paper I wish to analytically consider the impact of emotions upon the researcher, and consequently the research, and suggest that these can be very powerful tools through which to interpret and analyse data. Furthermore, I will argue that emotions are a valuable mechanism through which we can understand our participants and their environment, and therefore that when we disseminate our data, somewhere, to some extent, we must address emotions as an integral part of the research process. In particular, I want to focus upon the complexity of the research process in terms of how life and feelings (away from the field) can influence what the researcher is generating and how he or she goes about interpreting it.

This paper is taken from material gathered during an ESRC CASE (an Economic and Social Research Council collaborative funding scheme) doctoral studentship that has been co-funded by the City of London and the Institute of Cemetery and Crematorium Management. All fieldwork took place in the City of London Cemetery and Crematorium, a 220-acre site in Newham, East London, which celebrated its $150^{\text {th }}$ anniversary in 2006. This research project is an ethnographic study of how different groups of people perceive and experience the cemetery landscape, and the multiple meanings that can be uncovered at this one site. Whilst it has involved recording participants' accounts of their emotions and feelings within the cemetery as part of the data, I was naively unaware of how influential emotions can be within research at the time of collating this data, and it was not until after I left the field that I became 
sensitive to how constructive emotions can be for the researcher (Kleinman 1991). Thus, the paper is separated into a 'before', 'during', and 'after' the field, following the chronological development of social research, and the emotional journey that accompanies it.

Studying death is difficult. Along with birth, it is the one 'fact' of life that binds us all. Our impending death and mortality is not only innate but also penetrates all our understandings of ourselves and the world around us (Elias 1985), whether we deliberately acknowledge this or not. "Humans are the only creatures who not only know, but also know that they know - and cannot "unknown" their knowledge. In particular, they cannot "unknow" the knowledge of their mortality" (Bauman 1992:3). As a social anthropologist trying to produce analytical insights into how others experience and feel about sites of remembrance such as the cemetery, I was constantly reminded of Hertz's powerful observation that:

We all believe we know what death is because it is a familiar event and one that arouses intense emotion. It seems both ridiculous and sacrilegious to question the value of this intimate knowledge and to wish to apply reason to a subject where only the heart is competent. (Hertz 1960:27)

It is hard to be analytically detached when talking about death, thus I want to make it clear that this paper must be read as words directed from one mortal to another, grounded in the specific context of this research project, in this place, at this time. It is also on a 'topic' that will one day come to us all, whether experienced as our own death or that of others. There are no right or wrong answers in death, but if we recognise and incorporate the certainty of death, and our combined strength of human connectedness as mortals, we can perhaps come to appreciate the uniqueness of this subject, as both an academic and a personal one.

\section{Before the field}

As an ESRC CASE studentship, the aims and objectives for my doctoral project had already been negotiated between my supervisor and the City of London Cemetery director when I came on board the project in October 2003. As a result I was provided with predetermined research problems, which largely concentrated upon finding out which discourses of knowledge were being utilised and adopted by individuals and groups within the cemetery in order to interpret the practice and meanings of mourning behaviour. In addition, this piece of research had to produce a set of firm recommendations to satisfy its remit as a CASE project, including recommendations for conservation policy. In order to explore such a range of topics and issues, I took the decision early on to take an ethnographic approach to the research design, one that would enable me to incorporate many different methods (such as participant observation, interviews, photographic evidence and anecdotal information) in a flexible and responsive manner that would meet the standards of academia and the requirements of the funding collaborator. So, in partnership with my supervisor, I sat in my department in Sheffield, read a great number of texts on ethnography, and set about producing a coherent ethnographic plan that would enable me to access a range of views within the cemetery and meet the demands outlined above.

Fundamentally, within my ethnographic planning, my principal methodological choice of participant observation was driven by the idea that if I wanted to research practice, bodies and behaviour in the landscape, I had to actually be in that landscape. 
For the most part, this was motivated by my research interests in embodied experiences and activities that were taking place in this one site. In addition, guided partly by the outline I was given by my collaborative funding partners, I was concerned with how people individually contributed to a collective landscape aesthetic. Within the wider context of operating a cemetery site, these activities needed to be assessed and considered in the context of the cemetery providing a sustainable service, and in light of the status and role of the cemetery within the local community. Consequently, it was apparent to me that it was imperative that I was in this landscape, rather than looking at it from afar (Geertz 1974), in order to fully understand and experience the cemetery landscape from the numerous perspectives I was required to research.

Accordingly, I viewed myself very much as a vessel through which the research problem and the researched would come together (Burgess 1991) in what I (at the time) naïvely thought would be a predictable and straightforward way. Indeed, I relished the fact that I would have the opportunity to travel to my fieldsite in London and fulfil the conventional image of the intrepid researcher away from home. However, the reality of being in the cemetery was very different, as all my planning and anticipating did little to prepare me for the complex intellectual and emotional journey that was to come.

\section{In the field}

I entered the field in the summer of 2004, brimming with enthusiasm and waiting to uncover the 'answers' to what people were doing in the cemetery and why. Grounded in an ethnographic framework, I was confident that the use of participant observation was the best way to bring together an intellectual tradition with the actual lived experience of collecting data on a daily basis (MacLeod 1996). However, once I was in the field, the day-to-day generation of fieldnotes from observation in the cemetery was time consuming, wearisome, and most of all, a highly charged activity. Powerful feelings of guilt dogged me as I walked around the cemetery and tried to 'blend in' to my surroundings through a calculated management of my image (Hammersley and Atkinson 1983). I felt terribly deceitful watching people in the cemetery, who had no idea they were being critically observed with the intention of producing an academic piece of work. I had read a lot of literature on covert observation (Bulmer 1982, Hammersley and Atkinson 1983), but this had not equipped me for the reality of feeling so underhand, and the impossibility of 'neutralising' (Kleinman and Copp 1993:10) my feelings in the field. These strong reactions were further compounded by my loneliness in London, as I mostly stayed in anonymous hotels in unfamiliar areas. An extract from my personal field diary reflects how isolated and lacklustre I felt whilst in the field:

$1^{\text {st }}$ December 2004: beginning to see how this subject topic can really get me down... Had a rough last few weeks and just spent 4 day weekend fieldwork trip in London and felt so exhausted, lonely, fed up etc and it hit me that talking about grief, loss, loneliness etc, seeing sadness is just too much when not feeling at best. Need to talk to my supervisor about it really. Other than that feel a bit numb about PhD-flitter between liking doing fieldwork and feeling like 'I am a researcher' and 'what on earth am I doing?!'

At this point I was aware of the impact my emotional state could have on my data, but was preoccupied with being as 'professional' and as 'accurate' as possible, as I had 
strong feelings of accountability to my supervisors and collaborative partners. My interpretation of professionalism and accuracy was based on fulfilling the aims of the research project, and thus my focus at this time was on generating as much data and information as I could, of a quality and content that would fulfil the criteria for a doctoral thesis. These criteria I perceived as being as 'close' to the truth as possible, through the generation of a large amount of honest, frank, and 'neutral' data that could be analysed through the principles of grounded theory. I wanted to be saturated with data, so that the 'answers' to my research questions would become apparent through the coding process.

Whilst I was aware of being the vessel through which this data would be collated, at this stage I did not consider how my human-ness would affect what I saw, how I saw it, and what I recorded. However, it did not take long for me to realise that my (bordering on) obsession with accuracy and honest, frank data was not only unsustainable, but also unrealistic. In turn, moreover, this ambiguity of accuracy and honesty perpetuated a constant feeling of personal inadequacy, as I constantly felt I was falling short of the 'professional' aims I had created for myself through this desire to produce a high-quality doctoral thesis. As a result I found that:

fieldwork must certainly rank with the more disagreeable activities that humanity has fashioned for itself. It is usually inconvenient, to say the least, sometimes physically uncomfortable, frequently embarrassing, and to a degree, always tense. (Shaffir and Stebbins 1991:1)

Overall, most of my time spent in the field was emotionally draining and physically exhausting, and for the majority of my time I was pretty miserable. Not only that, but as time passed in the field I also found myself becoming increasingly sensitised to issues surrounding grief and mourning. Observing children's graves, particularly if they were born around the same time as me, or witnessing (what I guessed to be) parents attending a grave, often moved me greatly, frequently to tears. On one occasion I watched a man tending to a flowerpot by a grave with such devotion and intensity - he appeared oblivious to his immediate surroundings - that I had to leave the cemetery for a short while to get some physical distance from this force of grief. On other occasions, I could not approach visitors in the cemetery as I was too emotionally stirred by witnessing situations like that described above, or was simply too wary of being intrusive.

This led to further feelings of inadequacy as I perceived my inability to approach people (due to my emotional state) as unprofessional and not meeting the academic standards of a social researcher, as 'the conventional image of a researcher is someone who neutralizes his or her... viewpoints while conducting research' (Kleinman and Copp 1993:10). However, it has been through writing my thesis methodology and articles such as this paper that I have come to recognise and appreciate that these feelings are not only normal, but necessary in the production of data in sensitive areas. These realisations have served as a timely confirmation that I am a human being who is capable of experiencing a range of emotions, and can feel compassion and empathy towards others.

Thus I have reflected on moments like the one above and come to recognise how I dealt with being in the presence of such powerful emotions, not only as a researcher, but more importantly as a human being. In the field my most significant coping mechanism was to not make the connection between what I was observing and my own emotional state. I intentionally decided to view what I was seeing as 'data', as 
things that were happening to other people that could be interpreted analytically as a source of insights into behaviour in the cemetery. In this vein, in hindsight I believe that I was indeed at least trying to be accurate and 'truthful', even if I was personally having difficulty managing this. Furthermore, I did not relate my research to my own experiences of death and grief, or potential ones in the future. My research and my everyday identity were, to my mind, entirely separate.

In practical terms I came to depend heavily upon checklists (such as those proposed by Lofland and Lofland 1995) to ensure that I was covering all the salient points required in social research and thus maintaining academic standards. In retrospect these checklists acted as a symbolic barrier between the emotional nature of what I was observing and my own emotional self, as I used them to reassure myself that I was being a 'proper' researcher.

In addition, I spoke frequently with my supervisor and close family members, who acted as important sources of support and reassurance when I was at a low ebb. Indeed, I am indebted to their kindness and patience during this time, particularly when the division between what I was observing and my own feelings about death began to take their toll, as I neglected to appreciate the connections between my data and my emotional state in doing this type of fieldwork. This oversight reveals some of the complexities involved in 'becoming' a researcher, as I had not anticipated nor appreciated how demanding this fieldwork experience could be. Perhaps I should have heeded Coffey's warning that

we should never take for granted the physical and emotional demands of ethnographic work. Further, the physicality and emotionality of fieldwork should be seen as strengths, rather than burdens to be endured (1999:158)

However, whilst in the field, I simply did not make these connections, and it was not until I left the field to analyse and write up my data that I began to make the links between my emotional self and my research.

\section{After the field}

It was not until I was physically distanced from the field that I finally made these very powerful and important associations between my emotions and my data. Until this point I had viewed my observations and fieldnotes as unproblematic products of the ethnographic process, indeed, at this point I was more concerned with the volume of them than their content! During this period, however, I was also spending a lot of time thinking about death and becoming increasingly anxious about death happening to people I cared about, particularly my close family. Yet still I was not making the connection between my research project and my feelings. It was only when an acquaintance commented to me that I spoke about death a lot- even when not related to my doctorate - that I swiftly became aware that perhaps not everyone else (particularly my peer group) thought about death as much as I did.

This realisation was confirmed two weeks later when I attended the Death, Dying and Disposal Conference at the University of Bath in September 2005. As I sat listening to a discussion on the emotions a fellow researcher experienced when cleaning out her mother's attic after she died, it hit me how great the emotional impact of facing death and grief on a daily basis had actually been. This was something of a lightning bolt reaction, as all of a sudden - by seeing someone else making the link between their 
own personal experiences of death and their academic research-I became aware that I too was a human being who had personally experienced death and undoubtedly would experience more death in the future. By going into a cemetery and being surrounded by bereavement and grief, coupled with my personal experiences of death, I had become excessively concerned about death, experiencing firsthand what Giddens (1984) has referred to as a threat to my 'ontological security'. However, until this point I had not appreciated that what I was reading about and researching could actually have an effect on, and happen to, me. As naïve as it may sound, I had been so preoccupied with my professional role as a researcher and with generating data that would lead to a doctorate, that I had not considered that this subject of death was actually one that would affect $m e$ !

This was one of my most significant 'rites of passage' into the role of being a (more experienced) researcher (Peacock 2001), as I finally made the association between my own emotional state and the data and analysis I was producing. After this realisation, I returned to my fieldnotes with what felt very much like an 'enlightened eye' (Eisner 1993), and re-read them with an awareness of the emotional complexity of the research process. As a result of this, parts of the data rapidly 'came alive' under the new lens of emotion and a fresh analytical depth was suddenly evident within my reams of notes. What I had read before as a collection of quotes and observations from the cemetery landscape now became rich and highly charged data that could be interpreted as powerfully illuminating examples of how people went about expressing grief within this collective material environment.

An example of this new lens would be my new view of the intensity of the man tending to the flowerpot, as described earlier; whilst he was performing a common domestic task, the setting in which he was undertaking this activity added a new level of meaning in terms of how concentrated his efforts were. He was so very focused upon that flowerpot, that with my new 'enlightened eye', rather than being distracted by my own feelings of inadequacy when I had to leave the cemetery, I turned back to this data and reflected on why such a trivial task might be such an intense task in a cemetery. Partly, I concluded, it was because of the physical proximity to the grave, in the physical sense that he was kneeling directly in front of it. Other parts of my data suggested that gravestones were often used as physical representatives of the dead, and by performing this task in front of the grave, the man may have been performing a personal ritual for the deceased person by way of the gravestone. Thus, it is the context in which activities take place that is crucial to how we understand them, particularly whether they are inside or outside a cemetery (Hockey and Woodthorpe 2006).

Further insights into the cemetery world were as much about what was left unsaid, as about what was said, in interviews, as I realised the emotional complexities of what was taking place. Upon revisiting my data, another very powerful realisation was the invisibility of bodies and death. Very few participants mentioned death when I spoke to them in the cemetery, even fewer mentioned the body under the ground - and when they did it was to talk about the person sleeping, resting, or waiting to be reunited. The decomposition that happens in the ground was entirely hidden, as if out of sight, out of mind. People were not talking about the bodies in the ground, as we literally stood on top of them, and I did not recognise this dichotomy until I truly acknowledged the power of death, in terms of my own emotional reactions to it. 
A final new way of interpreting my data could also be seen in my observation fieldnotes. As the most time-consuming activity in my fieldwork day, I was often loath to write them, and even more reluctant to elaborate on them when I got back to my hotel room at night. Thus, I was rather hesitant to either read them, or analyse them, as I had such unenthusiastic feelings towards them. Again, it was not until I left the field and attended the Death, Dying and Disposal Conference in 2005 that I began to realise just perhaps why I felt so ambivalent towards my fieldnotes, and what they might illuminate in the cemetery: they were caught up with the very strong feelings of guilt mentioned earlier, and had become material records of my deception. However, as I had not liked committing anything to paper, I now viewed what I did commit as a useful indicator of what was going on, and I began to examine it in terms of why I had considered it so significant to note it down. Importantly, I began to see that these observations and comments from participants were no longer evidence of neutral data that I had collected from 'out there' in the field, they were data that I had been experiencing, both professionally and personally, whilst being in the field. Finally, I felt I understood what Geertz (1974) had meant.

Thus, this recognition of the relationship between emotion and research was a highly productive and constructive analytical development, as data that initially seemed limited or unimportant took on new meaning and enabled me to start making important links between what was going on in different parts of the cemetery, between different people, at different times. An example of this new illumination is the data I collected on the temporary ban placed upon cars being in the cemetery at weekends throughout 2005. At first, I viewed this ban and the subsequent outpouring of complaints as an operational health and safety issue that was being negotiated by the management of the cemetery. However, after recognising the power of emotions, I began to interpret this ban as perhaps more than an issue of mobility, questioning what the car actually meant to the person visiting the grave of their $\mathrm{mum} / \mathrm{dad} / \mathrm{son} /$ daughter/friend/lover. Through this fresh lens I analysed the data I had gathered on the banning of cars in terms of peoples' relationships with their dead and their familiar material environment, and considered why people were so terribly upset at not being allowed to drive to their grave. Thus I decided that it was more than an issue of access. This ban was about the relationship between the grave and the individual's wider domestic environment: the connection between the sacred and the profane in the cemetery landscape. The car connected the living with the dead physically but also in terms of familiarity, thus not being allowed to visit the grave with this sense of familiarity added another form of distance between the living and the dead. The car could thus be interpreted as a very important part of the symbolic connectedness between the living and the dead, providing a key link between the worlds of the living (the home) and the dead (the grave).

No longer anxious about my professionalism and commitment to the unsustainable notion of neutral accuracy, I was able to analyse my data with a new depth after these important moments of clarity. However, these emotional battles that have to be gone through to get to this point are not commonly discussed openly within research:

Anger, boredom, confusion, disgust, self-doubt, depression, lust, despair, frustration, and embarrassment are perhaps more than occasionally associated with fieldwork, but they are not often discussed-at least not in print-because such sentiments violate the pleasure principle so often associated with model practice. (Van Maanen, Manning and Miller 1993:vii) 
Thus, in generating credible social research, we need to move beyond conventional preoccupations of researcher objectivity and subjectivity (Hammersley 1990) and create a forum where these powerful and hugely influential rollercoasters of feeling can be acknowledged freely and incorporated into high-quality, credible qualitative research. 'Objectivity' and 'subjectivity' are unsustainable and unusable standards that cannot, and do not, fully incorporate the power of our emotional responses to the field, the data, and the analysis.

\section{Emotions in the research process}

I am basing my argument for the inclusion of emotions in the research process on Lakoff and Johnson's (1980) proposal that the concepts of objectivity and subjectivity are fundamentally unworkable standards for the human researcher to aspire to. In other terms, if we do not acknowledge the complexity of trying to accomplish these (unachievable) academic standards, we are doing an injustice to our data, our informants and our discipline by forcing our and their accounts into unsustainable frames of reference.

As anthropologists we are concerned with research among human beings by human beings, and thus as a fundamental part of human-ness, emotion cannot be left out of the ethnographic picture. It informs the way we negotiate, interpret and communicate our reality. As a result, when exploring people's realities we need to problematise the notion of, and indeed turn our attention reflexively to, our own problematic relationship with accuracy and honesty, to enable emotions to be incorporated and identified as a key analytical strength in our interpretation of the social world. Perhaps this is where Lakoff and Johnson's (1980) concept of 'inter-subjectivity' might be of most use; as a mechanism through which we can understand and appreciate our complex subjectivity. We can never be wholly objective or subjective in the uncomplicated way that these concepts are presented in research textbooks (such as Bryman 2004), as by being emotional creatures we are inherently flawed, prone to mistakes, and completely unique. How I might interpret the world out there might be very different to how you, the reader, might do. Indeed, how you or I might interpret this world might change depending on our feeling of self-esteem, mood and motivation, the time of day, the day of the week. Through my own experience, recognising and integrating emotions into my analysis has been a valuable tool through which I can understand my fieldnotes and my experiences in the cemetery landscape, and I urge others to do so, and to be as honest and frank in your writing as you can.

However, doing this is a risky business for social researchers, as by acknowledging our emotional status we can jeopardise our data and place ourselves in the vulnerable position of being accused of partiality and prejudice. Yet, by not doing this we can rightly be charged of being too positivistic in our mindset. As a result we need to recognise qualitative research as inherently a process of balance-balance between creating valid and credible research and analysis, that recognises ourselves, and our participants, as emotional and complex beings (an excellent example of this can be found in Lawton 2000). Rather than it being a case of whether the researcher does or does not reflect upon their role and emotions within their research, it is the extent to which that researcher acknowledges this that imparts credibility to a piece of analysis. What we need to consider is what insight into our informants' beliefs and experiences, and indeed our research question itself, can be developed from our emotional response 
to our data. It is an arrogant researcher who will dismiss their emotions and feelings and render them invisible in their analysis; to pretend that they are generating research from a distanced neutral standpoint. In contrast, it is the naïve researcher that will be so obsessed with accuracy and unsustainable academic standards that they are blinded to the emotionality of the human world. However, it is the misguided researcher who spends so much time being 'reflexive' that they fail to fully attend to the world within which their project is taking place. It is a case of 'hitting the right note' and incorporating all these issues into one credible piece of social research.

\section{Conclusion}

My research journey has been a complex and affecting one, but one that requires an element of reflection, particularly in relation to the topic under investigation. On a personal note I am still uneasy about death, but not so fearful of its impending inevitability, and now see my anxiety as a key empathetic strength in the analytical process. As a feeling human being I can share a certain amount of compassionate understanding with my grieving participants, and I believe it is essential to integrate this into my analysis.

Powerful emotional experiences in the field tell us, as researchers and readers, as much about the research process as the data itself. They can help us question why we, you, them, are doing what we are doing, and can draw us into the accounts of these experiences. Conventional understandings of what constitutes credible social research need to acknowledge the value of emotions, to the extent that researchers must address them somewhere in their analysis to ensure that they are indeed producing social research that is attaining to the academic research standards of accuracy and honesty. All research is generated and interpreted by the emotional researcher and reader. We need to recognise and understand it as such.

\section{References}

Bauman, Z. 1992. Morality, Immortality and Other Life Strategies, Cambridge: Polity Press.

Bryman, A. 2004. Social Research Methods, $2^{\text {nd }}$ ed. Oxford: Oxford University Press.

Bulmer, M. (ed.) 1982. Social Research Ethics: An Examination of the Merits of Covert Participation. London: Macmillan.

Burgess, R.G. 1991. In the Field: An Introduction to Field Research. London: Routledge.

Coffey, A. 1999. The Ethnographic Self: Fieldwork and the Representation of Identity. London: Sage.

Eisner, E.W. 1993. The Enlightened Eye: Qualitative Inquiry and the Enhancement of Educational Practice. New York: Macmillan Publishing.

Elias, N. 1985. The Loneliness of the Dying. Oxford: Blackwell Publishers.

Geertz, C. 1974. The Interpretation of Cultures. New York: Basic Books, Inc. Publishers. 
Giddens, A. 1984. The Constitution of Society: Outline of the Theory of Structuration. Cambridge: Polity.

Hammersley, M. 1990. Classroom Ethnography and Methodological Essays. Buckinghamshire: Open University Press.

Hammersley, M. and P. Atkinson. 1983. Ethnography: Principles in Practice. London: Tavistock Publications.

Hertz, R. 1960. Death and the Right Hand. London: Cohen and West.

Hockey, J. and K. Woodthorpe. Forthcoming 2006. Report on the Salon Professionel International de I'Art Funeraire, Paris, Le Bourget. Mortality 11(4).

Kleinman, S. 1991. Field-workers' feelings: what we feel, who we are, how we analyze. In Experiencing Fieldwork: An Inside View of Qualitative Research (eds.) W.B. Shaffir and R.A. Stebbins, 184-95. London: Sage.

Kleinman, S. and M.A. Copp. 1993. Emotions and Fieldwork. Qualitative Research Methods, volume 28. London: Sage.

Kreiger, S. 1996. Beyond subjectivity. In Journeys through Ethnography: Realistic Accounts of Fieldwork (eds.) A. Lareau and J. Shultz, 177-94. Oxford: Westview Press.

Lakoff, G. and M. Johnson. 1980. Metaphors We Live By. Chicago: Chicago University Press.

Lawton, J. 2000. The Dying Process. London: Routledge.

Lofland, J. and L.H. Lofland. 1995. Analyzing Social Settings: A Guide to Qualitative Observation and Analysis, $3^{\text {rd }}$ ed. London: Wadsworth Publishing Company.

MacLeod, J. 1996. On the making of ain't no making it. In Journeys through Ethnography: Realistic Accounts of Fieldwork (eds.) A. Lareau and J. Shultz, 111-48. Oxford: Westview Press.

Peacock, J.L. 2001. The Anthropological Lens: Harsh Light, Soft Focus, $2^{\text {nd }}$ ed. Cambridge: Cambridge University Press.

Shaffir, W.B. and R.A. Stebbins. (eds). 1991. Experiencing Fieldwork: An Inside View of Qualitative Research. London: Sage.

Van Maanen, J., P.K. Manning and M.L. Miller. 1993. Editors' introduction. In Emotions and Fieldwork by S. Kleinman and M.A Copp, vii-viii. London: Sage.

\section{Acknowledgements}

This paper is based on material from an Economic and Social Research Council CASE studentship, co-sponsored by the City of London and the Institute of Cemetery and Crematorium Management. Many thanks to Professor Jenny Hockey, Liz Woodthorpe and the anonymous reviewers for comments on earlier drafts of this paper. 


\section{About the author}

Kate Woodthorpe is in the final stages of her ESRC studentship in the Department of Sociological Studies at the University of Sheffield, under the principal supervision of Professor Jenny Hockey. Her doctoral project is seeking to examine how different groups of people perceive the cemetery landscape and how conflicts are negotiated, in light of current conservation priorities. She can be contacted at $\underline{\text { K.Woodthorpe@sheffield.ac.uk }}$ 